\title{
Home visits by paraprofessionals did not improve maternal and child health
}

Olds DL, Robinson J, O'Brien R, et al. Home visiting by paraprofessionals and by nurses: a randomized, controlled trial.

Pediatrics 2002;110:486-96.

\section{QUESTION: Do home visits by paraprofessionals (lay visitors/peer support or community workers) trained in a programme model that is effective when delivered by nurses, improve maternal and child health?}

\section{Design}

Randomised (allocation concealed), blinded (data collectors), controlled trial with follow up to 24 months postpartum.

\section{Setting}

21 antepartum clinics in Denver, Colorado, USA.

\section{Participants}

735 pregnant women (mean age 20 y) who had no previous live births and either qualified for Medicaid or had no health insurance. Follow up was $>80 \%$ for maternal interviews at $6,12,21$, and 24 months postpartum; and $83 \%$ for child assessment at 21 months of age.

\section{Intervention}

Participants were allocated to prenatal and postpartum $(\leq 24 \mathrm{mo}$ ) home visitation by paraprofessionals (PHV group, $\mathrm{n}=245$ ) or professional nurses (NHV group, $n=235)$, or to a control group ( $n=255)$. All home visitors received intensive training. Paraprofessionals were community workers with high school education but no postsecondary education. All participants received developmental screening and referral services for their children. The objectives of the home visitation programmes delivered by both groups included helping women to improve their health related behaviours during pregnancy and helping parents to provide more competent caregiving, plan future pregnancies, continue their education, and find work.

\section{Main outcome measures}

Maternal outcomes included changes in use of psychoactive substances in pregnancy (urine biomarkers at 36 wks gestation) and subsequent pregnancies (maternal interview at 24 mo postpartum); mother-infant interaction at 12, 15, 21, and 24 months postpartum. Child outcomes included measures of emotional and language development at 6 and 21 months of age, respectively.

\section{Main results}

Interactions between children and mothers who had low psychological resources were more responsive in the PHV group than in the control group (standard score points $99.45 v 97.54, \mathrm{p}=0.05$ ). The $\mathrm{PHV}$ group and the control group did not differ for other outcomes. Women in the NHV group had greater reductions in urine cotinine concentrations (259 $v 12 \mathrm{ng} / \mathrm{ml}, \mathrm{p}=0.03$ ), fewer subsequent pregnancies by 24 months after delivery of the first child (table), and more responsive interactions between children and mothers (standard score points $100 v 99, \mathrm{p}=0.05$ ) than did women in the control group. Fewer children in the NHV group than the control group showed emotional vulnerability in response to fear stimuli or language delays (table).

\section{Conclusion}

Maternal and child health did not improve after home visits by paraprofessionals trained in a programme model that is effective when delivered by nurses.
Sources of funding: The Colorado Trust; Department of Health and Human Services; and National Institute of Mental Health.

For correspondence: Dr D L Olds,

Prevention Research Center for Family and Child Health,

University of Colorado Health Sciences Center Denver, CO, USA. olds.david@tchden.org

\section{COMMENTARY}

A recent review of paraprofessional interventions for mothers of children $0-6$ years of age showed that effectiveness varies with educational background of the paraprofessionals, the quality and intensity of their training, and ongoing supervision. ${ }^{1}$ In this study, Olds et al assessed whether paraprofessionals could improve maternal and child health if they received training and supportive supervision in a programme model that is effective when delivered by nurses.

For most outcomes in which nurses produced beneficial effects, the effects of paraprofessionals were approximately half the size and not statistically significant. These findings are particularly notable given that paraprofessionals were similar to the visited mothers in social characteristics, and they received extensive training and regular supervision. However, this study did not address the effectiveness of nurses and paraprofessionals in situations where both may visit a family, or programmes in which other interventions beyond home visiting are included. The findings are generalisable to socially disadvantaged mothers and programmes that use visitors without professional training.

Current programming includes widespread use of paraprofessionals in home visiting. In view of the findings of Olds et al, paraprofessionals should only be used when the objectives are to improve maternal-child interactions among mothers with low psychological resources. Because most programmes have broader objectives, continued use of paraprofessionals should be questioned. Paraprofessionals were originally introduced, in part, as less costly home visitors than nurses. However, an economic analysis is needed to determine whether improved outcomes in women visited by nurses, such as an earlier return to work and fewer subsequent pregnancies, mean that nurses are more cost effective in the long run.

Helen Thomas, RN, MSc Associate Professor, McMaster University, Clinical Consultant, Hamilton Social, and Public Health Services Department, Hamilton, Ontario, Canada

1 Wade K, Cava M, Douglas C, et al. A systematic review of the effectiveness of peer/paraprofessional 1:1 interventions targeted towards mothers (parents) of 0-6 year old children in promoting positive maternal and/or child health development outcomes. Hamilton: Effective Public Health Practice Project, 1999. http://www.city.hamilton.on.ca/sphs/ephpp/ephppSumRev.htm

Home visitations by paraprofessionals (PHV) or nurses (NHV) v no visitations (control) in pregnancy and early childhood*

\begin{tabular}{|c|c|c|c|c|}
\hline Outcomes & Comparison & Event rates & RRR (Cl) & NNT (Cl) \\
\hline \multirow[t]{2}{*}{ Subsequent pregnancy at 24 months postpartum } & PHV $v$ control & $33 \% \vee 41 \%$ & $20 \%(-1$ to 36$)$ & Not significant \\
\hline & NHV $v$ control & $29 \%$ v $41 \%$ & $29 \%(9$ to 44$)$ & $9(5$ to 30$)$ \\
\hline \multirow[t]{2}{*}{ Children with emotional vulnerability at 6 months of age } & PHV $v$ control & $18 \%$ v $25 \%$ & $27 \%(-2$ to 48$)$ & Not significant \\
\hline & NHV $v$ control & $16 \%$ v $25 \%$ & $36 \%(8$ to 55$)$ & $12(7$ to 58$)$ \\
\hline \multirow[t]{2}{*}{ Children with language delays at 21 months of age } & PHV $v$ control & $11 \% \vee 12 \%$ & $9 \%(-47 \%$ to 44$)$ & Not significant \\
\hline & NHV $v$ control & $6 \% \vee 12 \%$ & $47 \%$ (6 to 71$)$ & $18(10$ to 160$)$ \\
\hline
\end{tabular}

*Abbreviations defined in glossary; RRR, NNT, and Cl calculated from data in article. 